
A $\mathbf{C}_{\text {ASE }} \mathbf{S}_{\text {Tudy }}$
FOOD SCIENCE
RESEARCH JOURNAL
- Visit us : www.researchjournal.co.in Volume 9 | Issue 2 | October, 2018 | 448-451
DOI : $10.15740 / \mathrm{HAS} / F S R J / 9.2 / 448-451$

\title{
An approach towards fortification of rice
}

\author{
Kiran Dabas and Khursheed Alam Khan
}

India is one of the largest producers of indigenous crops like rice, millets, wheat, maize and pulses. Inspite of having million of tonnes of production, people of different age group are suffering from the micronutrient deficiency diseases. National Family Health Survey (NHFS-4) shows that about 58 per cent of children, 53 per cent of women and 23 per cent of men are anemic and about 78 per cent of pregnant women are given iron and folic acid (IFA) pills in 2015-2016. However, only 30 per cent of pregnant women take pills at least for first 100 days of pregnancy (NFHS-4, 2016). The medium of providing iron and folic acid medication can be supported by intake of fortified rice due to its high consumption in India. About 104 million tonnes of rice produced in 2014-2015 and only 10 per cent of rice is exported and rest is consumed in India. Therefore, rice can be promoted as fortified indigenous crop to address micronutrient deficiency and will help in reducing anemia and pregnancy complications in women. Food regulatory authorities of India are also promoting the fortification in rice and wheat. This study investigates the effectiveness of various rice fortification techniques, advantages, disadvantages and recommendation for the promotion of fortified rice in rural and urban India. It elaborates the rice fortification through the process of parboiling, dusting, coating and extrusion processing.

Key Words : Micronutrients, Iron, Folic acid, Fortification, Parboiling

How to cite this article : Dabas, Kiran and Khan, Khursheed Alam (2018). An approach towards fortification of rice. Food Sci. Res. J., 9(2): 448-451, DOI : 10.15740/HAS/FSRJ/9.2/448-451. Copyright@ 2018: Hind Agri-Horticultural Society.

\footnotetext{
Author for correspondence :

Kiran Dabas, Department of Food Technology, Doon Valley Institute of Engineering and Technology, Kurukshetra University, Thanesar, Kurukshetra (Haryana) India

Associate Authors' :

Khursheed Alam Khan, Department of Agricultural Engineering, College of Horticulture, Mandsaur of Rajmata Vijayaraje Scindia Agriculture University, Gwalior (M.P.) India
} 